\title{
In vitro infectivity and differential gene expression of Leishmania infantum metacyclic promastigotes: negative selection with peanut agglutinin in culture versus isolation from the stomodeal valve of Phlebotomus perniciosus
}

Pedro J. Alcolea ${ }^{1 *}$, Ana Alonso ${ }^{1}$, María A. Degayón', Mercedes Moreno-Paz², Maribel Jiménez³ ${ }^{3}$ Ricardo Molina ${ }^{3}$ and Vicente Larraga ${ }^{1}$

\begin{abstract}
Background: Leishmania infantum is the protozoan parasite responsible for zoonotic visceral leishmaniasis in the Mediterranean basin. A recent outbreak in humans has been reported in this area. The life cycle of the parasite is digenetic. The promastigote stage develops within the gut of phlebotomine sand flies, whereas amastigotes survive and multiply within phagolysosomes of mammalian host phagocytes. The major vector of L. infantum in Spain is Phlebotomus perniciosus. The axenic culture model of promastigotes is generally used because it is able to mimic the conditions of the natural environment (i.e. the sand fly vector gut). However, infectivity decreases with culture passages and infection of laboratory animals is frequently required. Enrichment of the stationary phase population in highly infective metacyclic promastigotes is achieved by negative selection with peanut agglutinin (PNA), which is possible only in certain Leishmania species such as L. major and L. infantum. In this study, in vitro infectivity and differential gene expression of cultured PNA-negative promastigotes (Pro-PNA ${ }^{-}$) and metacyclic promastigotes isolated from the sand fly anterior thoracic midgut (Pro-Pper) have been compared.

Results: In vitro infectivity is about $30 \%$ higher in terms of rate of infected cells and number of amastigotes per infected cell in Pro-Pper than in Pro-PNA- This finding is in agreement with up-regulation of a leishmanolysin gene (gp63) and genes involved in biosynthesis of glycosylinositolphospholipids (GIPL), lipophosphoglycan (LPG) and proteophosphoglycan (PPG) in Pro-Pper. In addition, differences between Pro-Pper and Pro-PNA ${ }^{-}$in genes involved in important cellular processes (e.g. signaling and regulation of gene expression) have been found.

(Continued on next page)
\end{abstract}

\footnotetext{
* Correspondence: pjalcolea@cib.csic.es

'Laboratorio de Parasitología Molecular, Departamento de Microbiología

Molecular y Biología de las Infecciones, Centro de Investigaciones Biológicas

(Consejo Superior de Investigaciones Científicas), calle Ramiro de Maeztu, 9,

28040 Madrid, Spain

Full list of author information is available at the end of the article
}

CiöMed Central

C 2016 Alcolea et al. Open Access This article is distributed under the terms of the Creative Commons Attribution 4.0 International License (http://creativecommons.org/licenses/by/4.0/), which permits unrestricted use, distribution, and reproduction in any medium, provided you give appropriate credit to the original author(s) and the source, provide a link to the Creative Commons license, and indicate if changes were made. The Creative Commons Public Domain Dedication waiver (http://creativecommons.org/publicdomain/zero/1.0/) applies to the data made available in this article, unless otherwise stated. 
(Continued from previous page)

Conclusions: Pro-Pper are significantly more infective than peanut lectin non-agglutinating ones. Therefore, negative selection with PNA is an appropriate method for isolating metacyclic promastigotes in stationary phase of axenic culture but it does not allow reaching the in vitro infectivity levels of Pro-Pper. Indeed, GIPL, LPG and PPG biosynthetic genes together with a gp63 gene are up-regulated in Pro-Pper and interestingly, the correlation coefficient between both transcriptomes in terms of transcript abundance is $R^{2}=0.68$. This means that the correlation is sufficiently high to consider that both samples are physiologically comparable (i.e. the experiment was correctly designed and performed) and sufficiently low to conclude that important differences in transcript abundance have been found. Therefore, the implications of axenic culture should be evaluated case-by-case in each experimental design even when the stationary phase population in culture is enriched in metacyclic promastigotes by negative selection with PNA.

Keywords: Leishmania infantum, Metacyclic promastigotes, Phlebotomus perniciosus, Peanut lectin agglutination, Infectivity, Differential gene expression

\section{Background}

Leishmaniasis is a neglected vector-borne parasitic disease caused by protozoan parasites grouped into the genus Leishmania (Kinetoplastida: Trypanosomatidae). The estimated prevalence is 12 million people worldwide. The most severe clinical manifestation is visceral leishmaniasis (VL), which is fatal without treatment. About 60,000 deaths by VL are declared annually $[1,2]$. L. infantum is responsible for zoonotic VL in the Mediterranean basin and co-infection with HIV has been reported [3, 4]. Cutaneous and visceral signs are observed in the clinical profile of the canine reservoir. Recently, an outbreak in humans has been reported in central Spain, being hares reservoirs probably [5-7]. The life cycle of the parasite involves two stages: promastigotes and amastigotes. The promastigote is the fusiform motile extracellular stage with a flagellum emerging from the cellular body and the amastigote is the spherical immobile stage with a non-emergent flagellum. The developmental process of promastigotes is known as metacyclogenesis [8]. This process takes place within the gut of hematophagous sand flies (Diptera: Psychodidae, Phlebotominae), where different promastigote stages are observed (procyclics, haptomonads, nectomonads, leptomonads and metacyclics) [9]. When a sand fly vector feeds from a mammalian host, metacyclic promastigotes are injected in the dermis. Of those, few are internalized by phagocytes and differentiated to the amastigote stage under nitrosative stress, acidic $\mathrm{pH}$, increased temperature and the activity of acid hydrolases. Phlebotomus perniciosus is the most common sand fly vector in the center and the West of the Mediterranean basin $[10,11]$.

Several proteins are anchored to the surface of promastigotes through glycosylphosphatidylinositol (GPI). The gp63 surface protein (leishmanolysin) is an important metalloprotease associated to resistance to lysis by the complement system [12]. Other major molecules anchored to the plasma membrane are the lipophosphoglycan (LPG), the membrane-bound proteophosphoglycan (mPPG) and glycosylinositol phospholipids (GIPLs). It has been suggested that GIPLs protect the parasite against the hydrolytic enzymes of the parasitophorous vacuole (reviewed by [13]).

The sand fly gut is the natural microenvironment of promastigote differentiation to more infective nonproliferative metacyclic forms [14-16]. This process is often mimicked in vitro by axenization and culture at $26-27{ }^{\circ} \mathrm{C}$ in undefined media containing heat inactivated mammalian serum [17-22]. The main advantage of axenic cultures is that plenty of promastigote biomass is produced. However, attenuation of infectivity and virulence is observed accross culture passages, which is often remedied by passages through laboratory animals (reviewed in [21]). Differences between promastigotes in culture and within the sand fly in terms of promastigote development to the amastigote stage were already reported [23, 24].

Sacks and Perkins [15] described that procyclic $L$. major promastigotes, located in the abdominal gut of the sand fly, were not infective. Conversely, metacyclic promastigotes, located in the anterior part of the thoracic midgut, were able to produce infection in mice. Metacyclogenesis also takes place in axenic culture [16, 25]. Isolation of metacyclic $L$. major and $L$. infantum promastigotes is performed in culture on the basis of differential agglutination properties with the Arachys hypogaea lectin, the peanut agglutinin (PNA). Procyclic promastigotes are able to agglutinate because the lectin binds to the galactose residues of the LPG. These residues are blocked by arabinose ones that are added in the ongoing of metacyclogenesis leading to the loss of the agglutination capability. A differential centrifugation procedure allows the isolation of agglutinating procyclic (Pro-PNA ${ }^{+}$) and non-agglutinating metacyclic (Pro-PNA ${ }^{-}$) promastigotes within the stationary phase of axenic culture. Agglutination is reversible because dilution of the suspension leads to disappearance of the agglutination complexes. For 
this reason, additional PNA is required to maintain the appropriate concentration when the pellet is resuspended during the negative selection procedure of Pro-PNA ${ }^{-}$[26]. Genes related with infectivity are up-regulated in the minor Pro-PNA ${ }^{-}$promastigote subpopulation, which is more infective than the Pro-PNA ${ }^{+}$in L. infantum [26], as well as in L. major [25, 27-29].

Transcriptome analysis of metacyclic promastigotes isolated from the gut of the sand fly (Pro-Pper) is possible thanks to mRNA amplification [23]. Comparative in vitro infection and high throughput transcriptome analyses of Pro-Pper versus Pro-PNA ${ }^{-}$has been performed and their infectivity has been compared in vitro. Herein, we confirm that Pro-Pper metacyclic promastigotes are more infective than Pro- $\mathrm{PNA}^{-}$.

\section{Methods}

\section{Ethics statement}

Blood samples were extracted from a New Zealand White rabbit to feed $P$. perniciosus sand flies during infection with a suspension of phagocytic cells infected with $L$. infantum. The protocol was performed according to the EU (2010/63) and Spain (RD1201/2005) regulations and it was approved by the ISCIII Ethics Committee for Research in Animal Welfare (license CBA PA732011).

\section{Promastigote axenic culture}

Promastigotes of the MCAN/ES/98/10445 isolate (zymodeme MON-1) of Leishmania infantum were cultured at $27{ }^{\circ} \mathrm{C}$ in RPMI 1640 supplemented with L-glutamine (Lonza-Cambrex, Karlskoga, Sweden), 10 \% heat inactivated fetal bovine serum (HIFBS) (Lonza-Cambrex) and $100 \mu \mathrm{g} / \mathrm{ml}$ streptomycin - $100 \mathrm{IU} / \mathrm{ml}$ penicillin (LonzaCambrex). The inoccula were used at the $5^{\text {th }}$ passage after they had been obtained from the sand fly gut [23].

\section{Negative selection of metacyclic promastigotes with PNA} Stationary phase promastigotes were harvested at 2,000 g for $10 \mathrm{~min}$ and resuspended at a cell density of $2 \times 10^{8}$ cells $/ \mathrm{ml}$ in $10 \mathrm{ml}$ complete medium containing $50 \mu \mathrm{g} / \mathrm{ml}$ PNA [30]. Promastigotes were allowed to agglutinate at room temperature for $30 \mathrm{~min}$. Then, the sediment and the supernatant were recovered. The former was diluted to the initial volume in fresh complete medium containing $50 \mu \mathrm{g} / \mathrm{ml}$ PNA. Both fractions were centrifuged at $200 \mathrm{~g}$ for $10 \mathrm{~min}$ and the supernatants obtained were centrifuged at $2,000 \mathrm{~g}$ to obtain $\mathrm{PNA}^{-}$promastigotes $\left(\right.$Pro-PNA ${ }^{-}$). All steps were checked at the light microscope.

\section{In vitro infection of the human U937 myeloid cell line} The human cell line U937 (ATCC ${ }^{\bullet}$ CRL1593.2), originally obtained from a patient with histiocytic leukemia [31], was infected in vitro with $L$. infantum promastigotes for two different purposes: infection of sand flies to obtain promastigotes from the stomodeal valve (Pro-Pper) and evaluation of in vitro infectivity of Pro-PNA ${ }^{-}$and ProPper. First, the U937 cell line was cultured at $37{ }^{\circ} \mathrm{C}$ in complete medium in the presence of $5 \% \mathrm{CO}_{2}$ for $72 \mathrm{~h}$. Then, the cells were centrifuged at $250 \mathrm{~g}$ and differentiated in complete medium by stimulation with $20 \mathrm{ng} / \mathrm{ml}$ phorbol 12-myristate 13-acetate (Sigma, Saint Louis, MO) for $72 \mathrm{~h}$ [32]. This step was performed in a $175 \mathrm{~cm}^{2}$ flask when the resulting infected U937 cells were diluted in rabbit blood to infect sand flies experimentally (see below). In the case of evaluation of the in vitro infection capability of promastigotes, infections of U937 cells were performed over 8-well cell chamber slides (LabTek, New York, NY). The cultures were mildly rinsed with RPMI supplemented with L-glutamine (Lonza-Cambrex). Only, cells cultured in flasks were detached by vigorous shaking in the presence of $0.5 \mathrm{~g} / \mathrm{l}$ trypsin, $0.2 \mathrm{~g} / \mathrm{l}$ EDTA (LonzaCambrex). Trypsin was inactivated by adding one volume of complete medium. The differentiated cells were recovered by centrifugation. Then, they were mixed with stationary phase promastigotes at a promastigote:cell ratio 20:1 and incubated at $37^{\circ} \mathrm{C}$ in complete medium in a water bath for $2 \mathrm{~h}$. The mixture was mildly mixed every $15 \mathrm{~min}$. Once this incubation step was over, the cells were harvested and incubated again in the culture flasks in complete medium at $37{ }^{\circ} \mathrm{C}$, in an atmosphere of $5 \% \mathrm{CO}_{2}$ for $72 \mathrm{~h}$. The cultures were rinsed with complete medium after $2 \mathrm{~h}$ and $16 \mathrm{~h}$. Infections were checked at the light microscope with Giemsa stain prior to sand fly feeding. In the case of differentiated cells attached to the 8-well chamber slides, infections were performed at $37{ }^{\circ} \mathrm{C}$ at a promastigote:cell ratio 5:1 in $400 \mu \mathrm{l}$ complete medium in an atmosphere of $5 \% \mathrm{CO}_{2}$ for $2 \mathrm{~h}$. Next, the cells were rinsed with complete medium at 2 and $16 \mathrm{~h}$ post-infection as in the previous procedure. The incubations were resumed and samples were taken at 24,48 and $96 \mathrm{~h}$ postinfection to estimate the percentage of infected cells and the number of amastigotes per infected cell (100 cells were counted per sample). For this purpose, three more washes were performed prior to treatment with hypotonic solution $(180 \mu \mathrm{l}$ complete medium diluted with $220 \mu \mathrm{l}$ water per well) for $5 \mathrm{~min}$. Four washes with $150 \mu \mathrm{l}$ ethanolacetic acid 3:1 were carried out once the hypotonic solution had been removed. Then, fixation was performed with the same solution for $10 \mathrm{~min}$ and this step was repeated three times. Finally, cells were allowed to air dry and the wells removed from the slide. Modified Giemsa staining was performed with Diff-Quick ${ }^{\bullet}$ Stain Solution I and II (Dade Behring, Marburg, Germany). The preparations were washed with distilled water, air dried and mounted with Entellan ${ }^{\circ}$ Neu (Merck, Darmstadt, Germany). The percentage of infected cells and the number of amastigotes per infected cell were estimated in three biological 
replicate experiments and the statistical analysis was based on the Student's paired t-test.

\section{Infection of $P$. perniciosus and isolation of metacyclic promastigotes from the stomodeal valve}

An established colony of $P$. perniciosus sand flies [33] was maintained in a climatic chamber at $27-28{ }^{\circ} \mathrm{C}$, 90-100\% relative humidity, $17 \mathrm{~h}$ light $-7 \mathrm{~h}$ darkness photoperiod in the presence of a $30 \%$ fructose solution. About 150-200 sand flies were fed with a suspension of 2 x $10^{6}$ infected U937 cells in $2 \mathrm{ml}$ of defibrinated rabbit blood over a chicken skin membrane [34]. Sand fly samples were dissected daily in order to follow the course of infection. After 5 days, sand flies were dissected daily with the additional purpose of extracting the guts for isolation of mature promastigotes from the anterior thoracic midgut close to the stomodeal valve (Fig. 1) and subsequent preparation of RNA samples (see below). For this purpose, the gut was dissected to isolate the anterior part of the thoracic midgut and recover promastigotes in PBS with a Pasteur pipette. Three independent samples were prepared. Each one included promastigotes from about 20 infected sand flies. The replicate samples finally used had been obtained the day before the death phase started (day 6). This was also applicable for the equivalent Pro-PNA ${ }^{-}$population (see above).

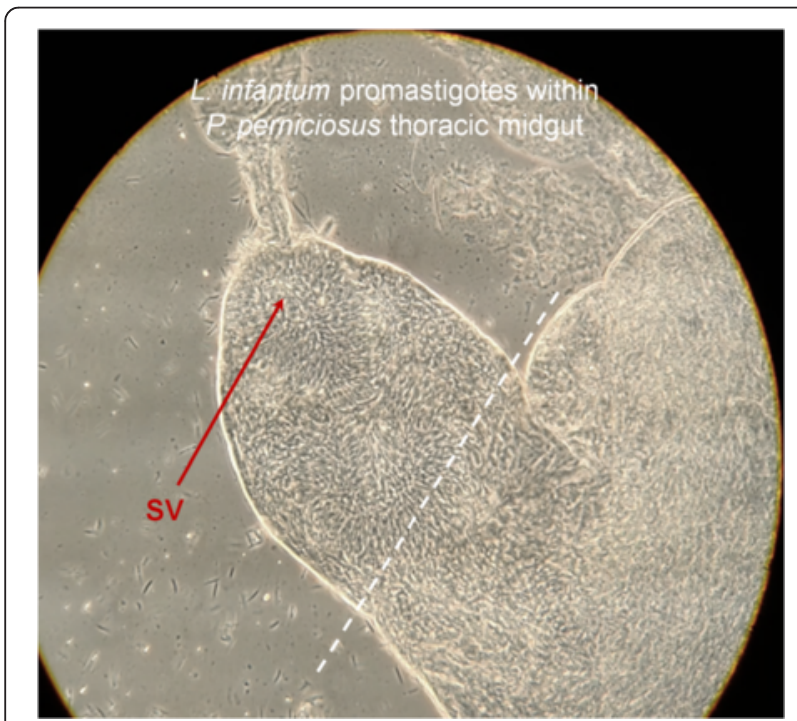

Fig. 1 Isolation of Pro-Pper. Promastigotes within the stomodeal valve of $P$. perniciosus. Sand flies were dissected and the guts separated. The abdominal gut and the posterior part of the thoracic midgut were discarded and Pro-Pper were recovered from the anterior part of the thoracic midgut (discontinuous line). The Pro-Pper population is enriched in metacyclic promastigotes as they are near the stomodeal valve (SV). Carryover of leptomonads was minimized by recovering just promastigotes in suspension and avoiding gut tissue as much as possible. However, it is assumed that this population is heterogeneous as expected in any biological experiment, as well as the Pro-PNA ${ }^{-}$population
RNA isolation, mRNA amplification and synthesis of labeled cDNA

Total RNA was purified from Pro-Pper and Pro-PNA ${ }^{-}$ with TRizol $^{\circ}$ reagent (Life Technologies, Carlsbad, CA) according to the manufacturer's instructions. One $\mu \mathrm{g}$ per $\mathrm{ml}$ of glycogen (Life Technologies) was added as carrier to the aqueous phase just before isopropanol precipitation. mRNA was doubly amplified (aaRNA) using MessageAmp ${ }^{\text {TM }}$ II aRNA Amplification Kit (Life Technologies) as previously described [24]. RNA quality was assessed with the Agilent 2100 Bioanalyzer (Life Technologies) in an RNA 6000 NanoChip according to the manufacturer's instructions.

The first strand aminoallyl-cDNA was synthesized using $10 \mu \mathrm{g}$ aaRNA template. First, aaRNA was mixed with $6 \mu \mathrm{g}$ of random hexamer primers (Life Technologies). The mixture was denatured at $70{ }^{\circ} \mathrm{C}$ for $10 \mathrm{~min}$ and immediately cooled. Then, first strand synthesis was performed at $46{ }^{\circ} \mathrm{C}$ in $30 \mu \mathrm{l}$ final reaction volume for $3 \mathrm{~h}$ with $570 \mu \mathrm{M}$ dATP, dCTP and dGTP, $230 \mu \mathrm{M}$ dTTP, $340 \mu \mathrm{M}$ aminoallyl-dUTP, $10 \mu \mathrm{M}$ DTT and $600 \mathrm{U}$ SuperScript $^{\circ}$ Reverse Transcriptase (Life Technologies). Next, RNA was degraded at $70{ }^{\circ} \mathrm{C}$ in $100 \mathrm{mM} \mathrm{NaOH} / 10 \mathrm{mM}$ EDTA for $30 \mathrm{~min}$ and the solution was then neutralized with $3 \mu \mathrm{l}$ of $3 \mathrm{M}$ sodium acetate pH5.2. AminoallylcDNA was purified with QiaQuick PCR Purification Kit (Qiagen, Hilden, Germany) according to the manufacturer's instructions except for two buffers: custom phosphate wash $(5 \mathrm{mM} \mathrm{KPO}, 80 \%$ ethanol, pH8.0) and phosphate elution ( $4 \mathrm{mM} \mathrm{KPO}_{4}$ ) buffers replaced those provided in the kit to avoid blockage of the amino group. Purified aminoallyl-cDNA was completely dried in a vacuum centrifuge and resuspended in $10 \mu \mathrm{l}$ of water. A solution containing the cyanine monofunctional dyes (Cy3 and Cy5; GE Healthcare, Chalfont Saint Giles, UK) were prepared at $12 \mathrm{ng} / \mu \mathrm{l}$ in DMSO. Coupling was allowed at room temperature in darkness for $1 \mathrm{~h}$ once $5 \mu \mathrm{l}$ of the Cy3 or Cy5 solution was added to the respective samples (Cy3 for Pro-PNA ${ }^{-}$and $\mathrm{Cy} 5$ for Pro-Pper). Finally, labelled cDNA was purified with QiaQuick PCR Purification Kit (Qiagen) according to the manufacturer's instructions.

\section{Microarray hybridization analysis of differential gene expression}

L. infantum shotgun genome microarrays [26] were washed in $0.1 \% \mathrm{~N}$-lauroylsarcosine in $2 \mathrm{X} \mathrm{SSC}$, then in 2X SSC. The slides were heated at $95{ }^{\circ} \mathrm{C}$ for $3 \mathrm{~min}$ and immediately chilled in $100 \%$ ethanol (10 s after removal from boiling water) thus denaturing and fixing DNA. The slide was spin dried in a minicentrifuge and attached upside down over a Hybri-Slip coverslip (Sigma) containing a $60 \mu \mathrm{l}$ drop of 3X SSC, $0.3 \%$ N-lauroylsarcosine, 60 mMTris- $\mathrm{HCl}$ pH8.0, $83 \mathrm{ng} / \mathrm{ml}$ denatured 
herring sperm DNA and $1 \%$ BSA. Blocking was allowed at $42{ }^{\circ} \mathrm{C}$ for $30 \mathrm{~min}$ using a hybridization chamber submerged in a water bath. Then, blocked microarrays were incubated at $40{ }^{\circ} \mathrm{C}$ for $16 \mathrm{~h}$ with a mixture of the Cy3- and Cy5-labelled cDNA samples (50 pmol dye each) in hybridization solution (equal to blocking solution except for $0.1 \% \mathrm{BSA}, 25 \mathrm{ng} / \mathrm{ml}$ poly $(\mathrm{T})$ and $50 \%$ deionized formamide). The slide was washed three times, first in 2X SSC, $0.2 \% \mathrm{SDS}$ at $40{ }^{\circ} \mathrm{C}$, then in $1 \mathrm{X} \mathrm{SSC}$ at room temperature and finally in 0.2X SSC at room temperature.

Hybridized microarrays were scanned with GenePix 4100A (Axon, Foster City, CA). Local feature background was subtracted from raw fluorescence intensity values with GenePix Pro 7.0 software. Raw data were normalized by the LOWESS per pin algorithm and Student's t-test contrast considering three biological replicates was performed with AlmaZen software (BioAlma, Tres Cantos, Spain). Differential expression cutoff values were applied to obtain the set of clones containing differentially regulated genes: (i) fold change $\mathrm{F} \geq 2(\mathrm{Cy} 5 / \mathrm{Cy} 3 \mathrm{ra}-$ tio if $\mathrm{Cy} 5>\mathrm{Cy} 3)$ or $\mathrm{F} \leq-2(-\mathrm{Cy} 3 / \mathrm{Cy} 5$ ratio if $\mathrm{Cy} 3>\mathrm{Cy} 5)$, (ii) total relative fluorescence intensity value $>5000$ arbitrary fluorescence units and (iii) $p^{*}<0.05$. The clones selected on the basis of these conditions were grown and sequenced with the M13-pUC18 primers and assembled as described [26]. These clones were classified according to the following genome alignment outcomes: (i) evalue $<1 \mathrm{e}-10$ for both ends, (ii) convergent orientation in the genome sequence and (iii) clone length $\leq 11 \mathrm{kbp}$ [26]. Type $a$ clones were defined by a unique pair of alignments. Type $b$ clones presented more than a pair of alignments due to adjoining sequence repeats; the best sequence identity is considered in this case. Finally, $c$ clones did not completely fulfill all three requirements, which is mostly due to the presence of two or more inserts in the clone or the lack of one of the end sequences. Clones were then associated to annotated genes using a Perl script.

\section{Real time quantitative RT-PCR (qRT-PCR)}

Synthesis of unlabeled single stranded cDNA was performed as indicated above except for the dNTP mixture (10 mM each dATP, dCTP, dGTP and dTTP in this case) The design of primers and FAM-MGB probes (Additional file 1: Table S1), configuration of 384-well plates and in situ synthesis was managed by Custom TaqMan Assays-byDesign (Life Technologies). The qRT-PCR assays were run in a 7900HT Fast Real Time PCR system (Life Technologies) once cDNA templates and TaqMan ${ }^{\circ}$ Universal Master Mix (Life Technologies) were added. Three sample replicates and three 1/10 dilutions of each one were included (25, 2.5 and $0.25 \mathrm{ng}$ cDNA in $15 \mu \mathrm{l}$ final reaction volume). Thermal cycling conditions were: $95{ }^{\circ} \mathrm{C}$ for 5 min; $40 \mathrm{x}$ [95 ${ }^{\circ} \mathrm{C}$ for 30s; $60{ }^{\circ} \mathrm{C}$ for $1 \mathrm{~min}$, data acquisition]. A $20 \%$ coefficient of variation cutoff was applied and PCR efficiencies were calculated by the standard curve best fit method [35]. Normalized quantities $\left(\mathrm{Q}_{\mathrm{n}}\right)$ were calculated by dividing the efficiency-corrected raw quantity values (equal to efficiency to the power of $-\mathrm{Ct}$ ) of the gene of interest by those of the reference gene ( $L$. infantum gGAPDH). Then, $\mathrm{F}$ was obtained by dividing $\mathrm{Q}_{\mathrm{n}}$ of both experimental conditions (Pro-Pper/Pro-PNA ${ }^{-}$) for each dilution. The mean $\mathrm{F}$ value and the $S D$ were calculated considering $Q_{n}$ values of all dilutions.

\section{Results and discussion}

Isolation of Pro-Pper and evaluation of in vitro infection In 1985 , it was described that $L$. major $\mathrm{PNA}^{-}$promastigotes are more infective than $\mathrm{PNA}^{+}$[27]. This was corroborated in $L$. infantum by us and up-regulated genes involved in infectivity were found [26]. In this study, Pro-Pper and Pro-PNA ${ }^{-}$have been compared in terms of in vitro infectivity and differential gene expression.

Digestive tracts were obtained from sand flies once they were dissected. The anterior thoracic midgut was selected (Fig. 1). Then, Pro-Pper promastigotes in suspension were recovered and carryover of gut tissue (and therefore leptomonads) was minimized. Three biological replicates of the experiments were performed. Pro-Pper samples obtained for evaluation of in vitro infection of U937 cells were recovered in PBS and immediately resuspended in $200 \mu \mathrm{l}$ complete medium. The suspension was added to PMA-differentiated U937 cells attached to 8-well slides and allowed to infect. After $2 \mathrm{~h}$ at $37{ }^{\circ} \mathrm{C}, 5 \% \mathrm{CO}_{2}$, the culture was washed to eliminate remaining promastigotes. Finally, samples were obtained at 24, 48 and 96 h postinfection. The same procedure was followed for Pro-PNA ${ }^{-}$. Then, the percentage of infected cells and the number of amastigotes per infected cell were estimated. Statistical analysis was performed by the unpaired Student's $t$ test. The reduction of in vitro infectivity in Pro-PNA ${ }^{-}$with respect to Pro-Pper in terms of rate of infected cells is 38, 22 and $22 \%$ at 24,48 and 96 h post-infection, respectively (Fig. 2a). The reduction in terms of average number of amastigotes per infected cell is 35,25 and $33 \%$ at 24,48 and 96 h postinfection, respectively (Fig. 2b). The differences were statistically significant in all cases $(p<0.001)$. Therefore, culture reduces the infection ability of promastigotes even when metacyclics are obtained by negative selection with PNA. Hence, this procedure is an appropriate method for isolation of metacyclics in culture but worse than isolation from the natural environment, i.e. the sand fly anterior thoracic midgut (Fig. 2).

\section{Transcript amplification and microarray hybridization analysis}

Pro-Pper samples used for gene expression analysis were immediately washed once in PBS and resuspended in 

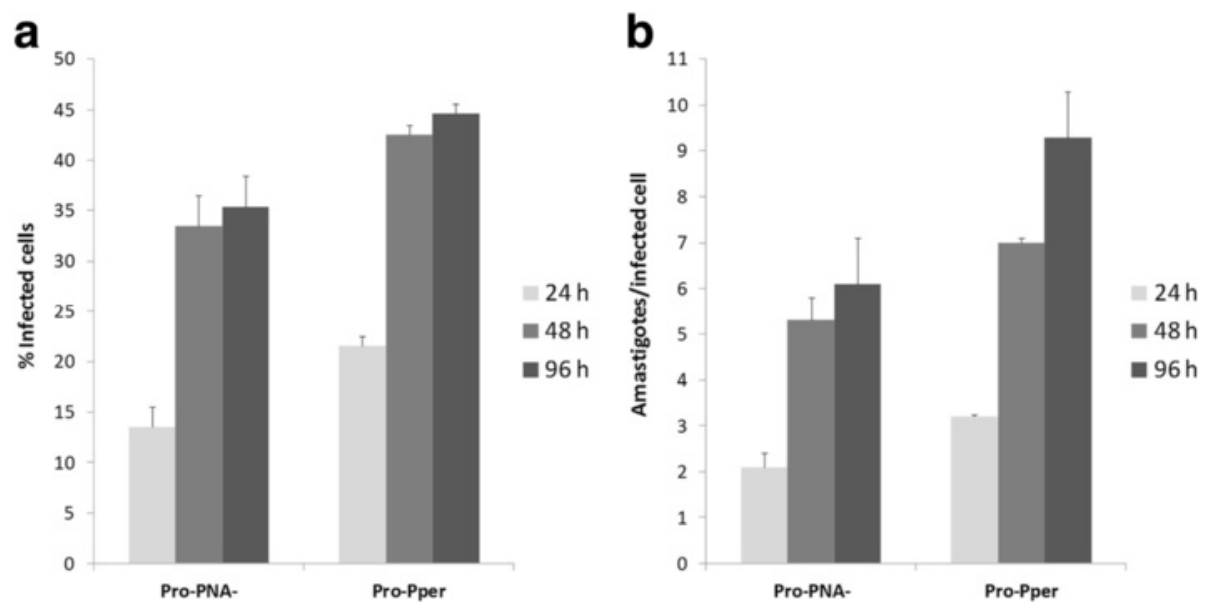

Fig. 2 In vitro infection of the stimulated U937 cell line with Pro-PNA ${ }^{-}$and Pro-Pper. All differences are statistically significant (unpaired Student's t-test, $p<0.001$ ). a Infection rate (\%). Mean \pm SD (Pro-PNA and Pro-Pper, respectively): $13 \pm 2$ and $21 \pm 1$ (24 h); $33 \pm 3$ and $42 \pm 1$ (48 h); $35 \pm 3$ and $45 \pm 1$ (96 h). b Number of amastigotes per infected cell. Mean \pm SD (Pro-PNA- and Pro-Pper, respectively): $2.1 \pm 0.3$ and $3.2 \pm 0.0$ (24 h); $5.3 \pm 0.5$ and $7.0 \pm 0.1(48 \mathrm{~h}) ; 6.0 \pm 1$ and $9 \pm 1(96 \mathrm{~h})$

TRIzol $^{\circ}$ reagent (Life Technologies). Then, two rounds of mRNA amplification were performed to obtain enough material for the high-throughput gene expression analysis. Obviously, Pro-PNA ${ }^{-}$sample processing was the same.

Several genes had been included in the microarrays as positive hybridization controls [26]. The stage-specific A2 amastigote gene [36] is not differentially expressed between Pro-Pper and Pro-PNA ${ }^{-}$(Additional file 2: Table S2) as expected. The fluorescence intensity values (FI) of all negative microarray hybridization controls are below the average background level as expected (Additional file 2: Table S2). The origin of these genes is the extremophile Leptospirillum ferrooxidans [26]. In total, 174 differentially regulated genes have been found: 111 are up-regulated in Pro-Pper and 63 in Pro-PNA ${ }^{-}$(Fig. 3, Tables 1 and 2,
Additional file 3: Tables S3-S5). The Pearson correlation coefficient between Pro-PNA ${ }^{-}$and Pro-Pper in terms of normalized fluorescence intensity values is $R^{2}=0.68$ (Fig. 3).

\section{qRT-PCR analysis}

Most clones overlapping with more than one gene annotation were analyzed by the TaqMan Probe qRT-PCR approach. Therefore, large clones that represent more than one CDS could be resolved. This approach was also useful to validate $26.3 \%$ of the microarray results (Tables 2 and 3), together with the internal hybridization controls already mentioned (Additional file 2: Table S2). Constant expression values were obtained just in the case of certain clones overlapping with more than one gene.

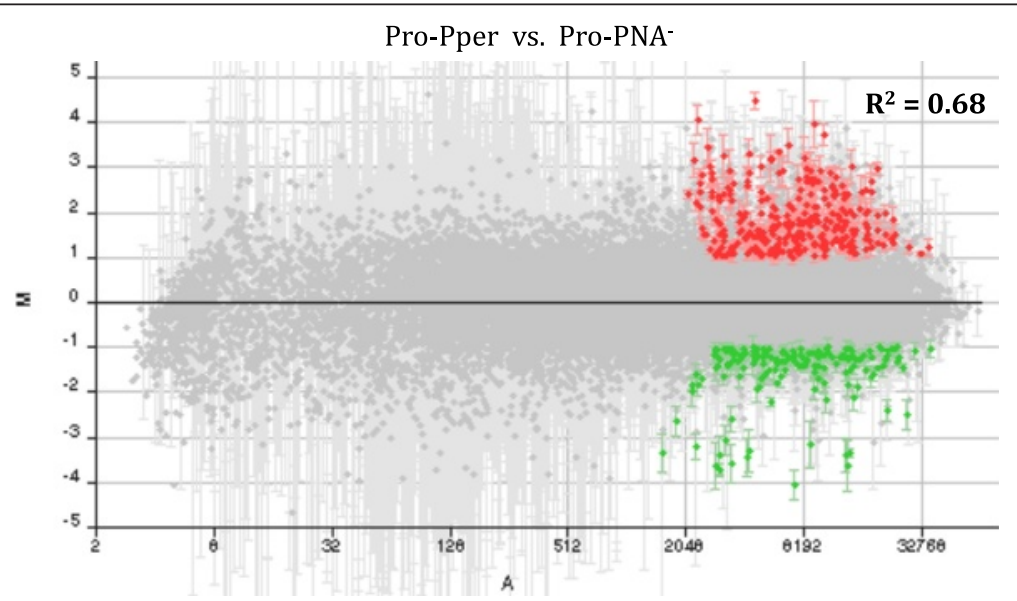

Fig. $3 \mathrm{M} / \mathrm{A}$ scatter plot of the three-replicate Pro-Pper/Pro-PNA ${ }^{-}$microarray hybridization experiment. $\mathrm{M}=\left(\log _{2} \mathrm{Ri}-\log _{2} \mathrm{Gi}\right)$ and $\mathrm{A}=\left[\left(\log _{2} \mathrm{Ri}+\log _{2} \mathrm{Gi}\right) /\right.$ 2], where $R$ and $G$ are, respectively, red (Cy5) and green (Cy3) fluorescence intensity values. Red spots represent selected clones that contain a gene up-regulated by at least 2 -fold and green spots represent those down-regulated by at least 2 -fold. The Pearson correlation coefficient $\left(R^{2}\right)$ is provided 
Table 1 Absolute frequencies of differentially regulated genes in Pro-Pper/Pro-PNA

\begin{tabular}{lll}
\hline Annotation status & \multicolumn{2}{l}{$\begin{array}{l}\text { Frequency of differentially regulated genes } \\
\text { in Pro-Pper/Pro-PNA }\end{array}$} \\
\cline { 2 - 3 } & Up-regulated & Down-regulated \\
\hline Genes of known function & 53 & 26 \\
Hypothetical protein genes & 56 & 31 \\
Type c clones & 2 & 6 \\
Total $(n=174)$ & 111 & 63 \\
\hline
\end{tabular}

\section{Differential gene expression between Pro-Pper and Pro-PNA}

In a study of differentiation of promastigotes to amastigotes, Lahav et al. [37] described that relative transcript levels do not correspond with abundance of the encoded protein in many cases. Indeed, coincidence was observed in just about $25 \%$ cases in quantitative terms (Pearson correlation coefficient). However, qualitative coincidences (constitutive expression, upregulation and down-regulation) were observed in $65 \%$ cases (589 out of 902 genes). As we have seen, one of the purposes of this study is comparing Pro-PNA ${ }^{-}$and Pro-Pper in terms of relative transcript abundance, focusing on differentially regulated genes. For this purpose, the qualitative information is more relevant than the quantitative because it provides a picture of the steady-state transcript levels in both conditions. Hence, insight into the adequacy of negative selection of metacyclics in culture with PNA compared to the natural environment (the sand fly gut) is provided herein. Additionally, the different approaches used (e.g. microarray hybridization analysis and qRT-PCR in this study) have different dynamic ranges and sometimes provide different quantitative results for coincident qualitative results. In conclusion, the transcriptome analysis is useful in this study and it is the only possibility to study gene expression in Pro-Pper so far. In fact, the negligible amount of parasite material obtained from sand fly dissections does not allow performing analysis of individual proteins and the proteome, whereas it is possible to amplify RNA. In our case, 174 genes are differentially regulated between Pro-PNA ${ }^{-}$and Pro-Pper. Therefore, we expect about 113 genes showing the same qualitative outcome of relative abundance at the transcript and protein levels.

The comprehensive study of the differences found in transcript abundance is illustrated in Fig. 4. The most striking qPCR results are illustrated in Fig. 5. Provided that unequivocal identification is very important [38], gene name abbreviations have been included in Tables 2 and 3. Unless otherwise indicated, the term up-regulation refers to Pro-Pper and downregulation to Pro- $\mathrm{PNA}^{-}$.

\section{Chromatin structure, nucleocytoplasmic transport and} regulation of gene expression at the post-transcriptional and post-translational levels

Three up-regulated genes in Pro-Pper involved in DNA replication and chromatin remodeling have been found: histone (H3), SNF2/RAD54 helicase and minichromosome maintenance protein $(\mathrm{mcm})$. Metacyclic promastigotes are non-dividing forms of the parasite, but $\mathrm{H} 3$ gene over-expression is in agreement with independence of mRNA levels from DNA synthesis [39].

A nuclear movement protein gene (NUDC) is upregulated in Pro-Pper, whereas two major vault protein genes (MVP) are down-regulated. This suggests differences in nucleocytoplasmic transport and signaling between Pro-Pper and Pro-PNA ${ }^{-}$. In fact, MVPs are the main constituents of vaults, which are protein complexes that may participate in both processes [40] and they are able to interact with the target of rapamycin protein 4 (TOR4) in Trypanosoma brucei [41].

A transcription factor-like protein gene (TF-like) and the RNA helicase LinJ.15.0130 are up-regulated in ProPper. As for translation regulation, several genes are differentially regulated between both populations of metacyclics. On the one hand, the elongation factor $1 \beta$ (EF1 $\beta$ ), the initiation factor 2 (IF2), the $40 \mathrm{~S}$ ribosomal proteins S8, S19 and S30, the 60S ribosomal proteins L14, L36 and L37a and the glycyl-tRNA synthetase are up-regulated. On the other hand, the diphthine synthase gene, the ribosomal proteins S2 and L3 are downregulated. The EF1 $\beta$ is up-regulated by cadmium [42], whereas the IF2 is up-regulated in stationary phase promastigotes with respect to intracellular amastigotes [24]. Diphthine is the direct precursor of diphthamine, a molecule able to inactivate the IF2 by addition of a residue of ADP-ribose, as the diphtheria toxin does [43]. Downregulation of the diphthine synthase $(\mathrm{DpS})$ in Pro-Pper (Table 3) is in agreement with up-regulation of the IF2. Finally, the cyclophilin genes CYP3 and CYP11, involved in protein folding, are up-regulated.

\section{Proteolysis}

The oligopeptidase $\mathrm{B}$ gene (OPB) is up-regulated in ProPper, whereas the calpain-like cysteine peptidase $(\mathrm{C} 2 \mathrm{Cp})$ LinJ.31.0480 is down-regulated. The results found also suggest changes in ubiquitin-proteasome protein degradation pathway between Pro-Pper and Pro-PNA ${ }^{-}$, as the ubiquitin activating enzyme E1 gene (UbqA-E1), the E3 activating protein cullin and the ubiquitin hydrolase $(\mathrm{UbH})$ are up-regulated.

\section{Protein-protein interaction}

A leucine-reach repeat protein (LRRP) of unknown function in the parasite is up-regulated in Pro-PNA ${ }^{-}$. LRRPs have been associated to functions generally involving 
Table 2 Genes of known function up-regulated in Pro-Pper/Pro-PNA

\begin{tabular}{|c|c|c|c|c|c|c|}
\hline Clone & $F$ & $\log _{2} F \pm S D$ & $p$ & & & Def. \\
\hline & & & & $F w$ & $R v$ & \\
\hline Lin85D8 & 3.07 & $1.6 \pm 0.1$ & 0.047 & 0 & 0 & $\mathrm{~b}$ \\
\hline & & & & & & \\
\hline Lin86D3 & 8.13 & $3.0 \pm 0.2$ & 0.000 & 0 & $9 \mathrm{e}-37$ & b \\
\hline Lin89E3 & 3.35 & $1.7 \pm 0.2$ & 0.044 & $7 e-96$ & 0 & b \\
\hline Lin88E3 & 2.20 & $1.1 \pm 0.2$ & 0.002 & 0 & 0 & b \\
\hline Lin96Cl & 2.88 & $1.5 \pm 0.4$ & 0.009 & 0 & 0 & b \\
\hline Lin100B12 & 4.88 & $2.3 \pm 0.4$ & 0.021 & 0 & 0 & b \\
\hline & & & & & & \\
\hline & & & & & & \\
\hline Lin121C6 & 2.68 & $1.4 \pm 0.6$ & 0.006 & 0 & 0 & b \\
\hline Lin142C8 & 3.28 & $1.7 \pm 0.4$ & 0.025 & 0 & 0 & $\mathrm{a}$ \\
\hline & & & & & & \\
\hline & & & & & & \\
\hline & & & & & & \\
\hline Lin143C12 & 2.24 & $1.2 \pm 0.7$ & 0.004 & 0 & 0 & $\mathrm{~b}$ \\
\hline & & & & & & \\
\hline Lin145Al & 3.55 & $1.8 \pm 0.3$ & 0.009 & 0 & 0 & b \\
\hline & & & & & & \\
\hline & & & & & & \\
\hline & & & & & & \\
\hline $\operatorname{Lin} 146 \mathrm{~A} 12$ & 3.07 & $1.6 \pm 0.3$ & 0.003 & 0 & 0 & b \\
\hline & & & & & & \\
\hline & & & & & & \\
\hline & & & & & & \\
\hline Lin151C7 & 2.01 & $1.0 \pm 0.3$ & 0.026 & 0 & 0 & b \\
\hline & & & & & & \\
\hline Lin155B1 & 2.29 & $1.2 \pm 0.2$ & 0.033 & 0 & 0 & b \\
\hline Lin158C1 & 2.82 & $1.5 \pm 0.1$ & 0.004 & 0 & 0 & b \\
\hline Lin159D8 & 2.76 & $1.5 \pm 0.8$ & 0.016 & 0 & 0 & b \\
\hline & & & & & & \\
\hline Lin169A11 & 3.89 & $2.0 \pm 0.2$ & 0.014 & 0 & 0 & a \\
\hline & & 2.010 .2 & . & - & . & ( \\
\hline Lin169G11 & 2.35 & $1.2 \pm 0.1$ & 0.039 & 0 & 0 & b \\
\hline & & & & & & \\
\hline Lin169E6 & 2.85 & $1.5 \pm 0.3$ & 0.015 & 0 & 0 & b \\
\hline Lin170B7 & 2.67 & $1.4 \pm 0.9$ & 0.033 & 0 & 0 & $\mathrm{a}$ \\
\hline Lin175D9 & 2.84 & $1.5 \pm 0.5$ & 0.018 & $5 e-63$ & $4 \mathrm{e}-57$ & a \\
\hline Lin177E10 & 3.50 & $1.8 \pm 0.1$ & 0.021 & 0 & 0 & b \\
\hline Lin177F8 & 2.14 & $1.1 \pm 0.1$ & 0.032 & 0 & 0 & a \\
\hline Lin178A5 & 2.74 & $1.4 \pm 0.5$ & 0.011 & 0 & 0 & b \\
\hline Lin179C9 & 3.42 & $1.8 \pm 0.3$ & 0.039 & 0 & 0 & b \\
\hline Lin179E10 & 3.58 & $1.8 \pm 0.3$ & 0.042 & 0 & 0 & $\mathrm{~b}$ \\
\hline & & & & & & \\
\hline Lin185G7 & 5.56 & $2.4 \pm 0.4$ & 0.008 & $2 \mathrm{e}-28$ & $1 \mathrm{e}-11$ & $\mathrm{a}$ \\
\hline Lin187C5 & 3.99 & $2.0 \pm 0.3$ & 0.028 & 0 & 0 & b \\
\hline ter & . & 2.010 .0 & (1) & 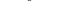 & - & 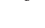 \\
\hline Lin187C7 & 2.54 & $1.3 \pm 0.3$ & 0.040 & 0 & 0 & b \\
\hline & & & & & & \\
\hline & & & & & & \\
\hline $\operatorname{Lin} 187 \mathrm{C} 10$ & 4.78 & $2.3 \pm 0.4$ & 0.006 & 0 & 0 & b \\
\hline Lin188B1 & 2.50 & $1.3 \pm 0.1$ & 0.044 & 0 & 0 & a \\
\hline & & & & & & \\
\hline Lin188C9 & 2.11 & $1.1 \pm 0.6$ & 0.000 & 0 & 0 & $\mathrm{a}$ \\
\hline Lin189B12 & 2.24 & $1.2 \pm 0.2$ & 0.029 & 0 & 0 & a \\
\hline & & & & & & \\
\hline Lin196B3 & 2.28 & $1.2 \pm 0.1$ & 0.003 & 0 & 0 & b \\
\hline Lin202E4 & 3.40 & $1.8 \pm 0.8$ & 0.000 & 0 & 0 & b \\
\hline Lin208F7 & 3.07 & $1.6 \pm 1.1$ & 0.038 & 0 & 0 & b \\
\hline Lin212G5 & 2.09 & $1.1 \pm 0.3$ & 0.009 & 0 & 0 & b \\
\hline Lin215A7 & 2.68 & $1.4 \pm .56$ & 0.006 & 0 & 0 & a \\
\hline & & & & & & \\
\hline Lin220A9 & 5.42 & $2.4 \pm 0.5$ & 0.013 & 0 & 0 & a \\
\hline Lin221G3 & 2.28 & $1.2 \pm 0.4$ & 0.035 & 0 & 0 & b \\
\hline & & & & & & \\
\hline Lin232G3 & 2.35 & $1.2 \pm 0.4$ & 0.029 & $2 \mathrm{e}-74$ & $5 e-72$ & $\mathrm{a}$ \\
\hline Lin240D3 & 3.51 & $1.8 \pm 0.7$ & 0.039 & 0 & 0 & c \\
\hline & & & & & & \\
\hline & & & & & & \\
\hline Lin250G8 & 2.91 & $1.5 \pm 0.4$ & 0.049 & 0 & 0 & b \\
\hline & & & & & & \\
\hline Lin255D9 & 3.15 & $1.7 \pm 0.6$ & 0.004 & $6 e-112$ & $2 \mathrm{e}-111$ & $\mathrm{a}$ \\
\hline Lin267E5 & 2.30 & $1.2 \pm 0.5$ & 0.046 & 0 & 0 & $\mathrm{a}$ \\
\hline $\operatorname{Lin} 272 \mathrm{~A} 3$ & 3.49 & $1.8 \pm 0.2$ & 0.036 & 0 & 0 & b \\
\hline & & & & & & \\
\hline & & & & & & \\
\hline Lin288H7 & 3.19 & $1.7 \pm 1.1$ & 0.049 & 0 & 0 & b \\
\hline & & & & & & \\
\hline Lin289A8 & 2.56 & $1.3 \pm 0.5$ & 0.034 & 0 & 0 & b \\
\hline Lin292G5 & 3.57 & $1.8 \pm 0.8$ & 0.000 & 0 & 0 & $\mathrm{a}$ \\
\hline & & & & & & \\
\hline Lin296F4 & -2.14 & $-1.1 \pm 0.2$ & 0.032 & 0 & 0 & b \\
\hline & & & & & & \\
\hline Lin302E4 & 3.12 & $1.6 \pm 0,4$ & 0.002 & 0 & 0 & $\mathrm{a}$ \\
\hline & & & & & & \\
\hline Lin308A8 & 2.62 & $1.4 \pm 0.4$ & 0.038 & 0 & 0 & $\mathrm{~b}$ \\
\hline & & & & & & \\
\hline & & & & & & \\
\hline Lin312F4 & 5.31 & $2.4 \pm 0.4$ & 0.034 & 0 & $1 \mathrm{e}-82$ & b \\
\hline & & & & & & \\
\hline & & & & & & \\
\hline
\end{tabular}

Features described: clone number, fold change (up-regulation if $F \geq 2.0$ ), $\log _{2} \mathrm{~F}$ and standard deviation (SD), Student's t-test $p$-value (p), clone definition (Def.; see Methods), TriTrypDB identifier, annotated gene function (including abbreviations defined in the text) and qRT-PCR outcome. Genes in grey (clones that overlap with more than one annotated gene): they are not differentially regulated (confirmed by qRT-PCR) or there is no evidence to support that they are differentially regulated in other cases (not determined by qRT-PCR) 
Table 3 Genes of known function down-regulated in Pro-Pper/Pro-PNA

\begin{tabular}{|c|c|c|c|c|c|c|c|c|c|c|}
\hline \multirow[t]{2}{*}{ Clone } & \multirow[t]{2}{*}{$F$} & \multirow[t]{2}{*}{$\log _{2} F \pm S D$} & \multirow[t]{2}{*}{$p$} & \multicolumn{2}{|c|}{ e-value } & \multirow[t]{2}{*}{ Def. } & \multirow[t]{2}{*}{ TriTrypDB Id. } & \multirow[t]{2}{*}{ Annotated gene function } & \multirow{2}{*}{\multicolumn{2}{|c|}{$\begin{array}{r}q R T-P C R \\
F \pm S D\end{array}$}} \\
\hline & & & & $F w$ & $R v$ & & & & & \\
\hline Lin85F11 & -2.67 & $-1.4 \pm 0.2$ & 0.040 & $1 \mathrm{e}-156$ & $2 \mathrm{e}-158$ & $\bar{a}$ & LinJ.34.4160 & Phosphatidylinositol 3-kinase-like protein (TOR2) & N.D. & \\
\hline Lin105H12 & -2.04 & $-1.0 \pm 0.1$ & 0.012 & 0 & 0 & a & LinJ.27.1700 & Protein kinase-like protein $(\mathrm{PK})$ & N.D. & \\
\hline Lin106G6 & -2.87 & $-1.5 \pm 1.2$ & 0.021 & 0 & 0 & a & $\begin{array}{l}\text { LinJ.32.0460 } \\
\text { LinJ.32.0470 }\end{array}$ & $\begin{array}{l}\text { 40S ribosomal subunit } \mathrm{S} 2 \text {, putative } \\
\text { Prostaglandin } \mathrm{F} \text { synthase, putative }\end{array}$ & + & $\begin{array}{l}-2.2 \pm 0.3 \\
-1.2 \pm 0.1\end{array}$ \\
\hline Lin110G8 & -2.02 & $-1.0 \pm 0.2$ & 0.013 & 0 & 0 & $\mathrm{~b}$ & LinJ.31.0480 & $\begin{array}{l}\text { Calpain-like cysteine peptidase, Clan CA. family C2, putative } \\
\text { (C2cp) }\end{array}$ & N.D. & \\
\hline Lin $125 \mathrm{H} 7$ & -2.04 & $-1.0 \pm 0.2$ & 0.035 & 0 & 0 & $\mathrm{~b}$ & LinJ.28.3110 & Dynein-light chain, putative (DynLC) & N.D. & \\
\hline Lin139A6 & -2.32 & $-1.2 \pm 0.4$ & 0.008 & $6 e-158$ & $6 e-81$ & $\mathrm{~b}$ & LinJ.02.0100 & Phosphatidylinositol 3-kinase-like protein (PI3K) & N.D. & \\
\hline Lin144A12 & -2.31 & $-1.2 \pm 0.3$ & 0.029 & 0 & 0 & a & LinJ. 15.0800 & ATP-binding cassete 1 -like protein $(\mathrm{ABCl})$ & N.D. & \\
\hline Lin148A8 & -2.17 & $-1.1 \pm 0.6$ & 0.042 & 0 & 0 & $\mathrm{~b}$ & $\begin{array}{l}\text { LinJ.21.0720 } \\
\text { LinJ.21.0730 }\end{array}$ & $\begin{array}{l}\text { Nucleotide-binding protein, putative (NBP-MRP) } \\
\text { Metallo- } \beta \text {-lactamase family protein, putative }\end{array}$ & + & $\begin{aligned}-7.9 \pm 0.1 \\
1.1 \pm 0.3\end{aligned}$ \\
\hline Lin166E5 & -2.11 & $-1.1 \pm 0.6$ & 0.030 & 0 & 0 & b & LinJ.20.0970 & Protein kinase, putative (PK) & N.D. & \\
\hline Lin167D1 & -2.38 & $-1.2 \pm 0.2$ & 0.037 & 0 & 0 & b & LinJ.20.0970 & Protein kinase, putative (PK) & N.D. & \\
\hline $\operatorname{Lin} 172 \mathrm{C} 3$ & -2.23 & $-1.1 \pm 0.2$ & 0.007 & $2 e-71$ & $6 e-75$ & a & LinJ.04.0470 & ADP-ribosylation factor, putative (ARF) & N.D. & \\
\hline Lin185G3 & -2.45 & $-1.3 \pm 0.2$ & 0.028 & 0 & 0 & a & LinJ.21.0260 & Major vault protein (MVP) & N.D. & \\
\hline Lin182D9 & -2.28 & $-1.2 \pm 0.1$ & 0.034 & 0 & 0 & b & LinJ.06.0860 & Lipin, putative & N.D. & \\
\hline Lin188B3 & -2.69 & $-1.4 \pm 0.3$ & 0.031 & 0 & 0 & $\mathrm{~b}$ & LinJ. 30.3230 & $\begin{array}{l}\text { 3-hydroxy-3-methylglutaryl-CoA reductase, putative } \\
\text { (HMGCR) }\end{array}$ & N.D. & \\
\hline Lin197G1 & -2.18 & $-1.1 \pm 0.1$ & 0.004 & 0 & 0 & $\mathrm{~b}$ & LinJ.05.0060 & Major vault protein, putative (MVP) & N.D. & \\
\hline Lin209G10 & -3.80 & $-1.9 \pm 0.6$ & 0.027 & $1 \mathrm{e}-60$ & $5 e-63$ & $\mathrm{~b}$ & LinJ.34.2730 & Ribosomal protein L3, putative & N.D. & \\
\hline Lin221E12 & -2.18 & $-1.1 \pm 0.3$ & 0.049 & 0 & 0 & a & LinJ.09.0580 & Leucine-rich repeat protein, putative (LRRP) & N.D. & \\
\hline Lin228H3 & -3.09 & $-1.6 \pm 0.3$ & 0.007 & 0 & 0 & a & $\begin{array}{l}\text { LinJ. } 31.3250 \\
\text { LinJ.31.3260 }\end{array}$ & $\begin{array}{l}\text { Phosphatidylethanolamine } \mathrm{N} \text {-methyltransferase, putative } \\
\text { Methylcrotonyl-CoA carboxilase biotinylated subunit (MCCbt) }\end{array}$ & - & $\begin{array}{r}1.0 \pm 0.1 \\
-2.1 \pm 0.3\end{array}$ \\
\hline $\operatorname{Lin} 243 \mathrm{~A} 10$ & -3.18 & $-1.7 \pm 0.9$ & 0.037 & $4 \mathrm{e}-125$ & $1 e-125$ & a & LinJ.31.1640 & Dipthine synthase-like protein (DpS) & N.D. & \\
\hline Lin241A4 & -2.84 & $-1.5 \pm 0.3$ & 0.014 & $3 e-67$ & $1 \mathrm{e}-23$ & a & LinJ. 23.0290 & Multi-drug resistance protein, putative (MRP) & N.D. & \\
\hline Lin282B9 & -8.43 & $-3.1 \pm 0.9$ & 0.047 & $5 \mathrm{e}-177$ & 0 & $\mathrm{~b}$ & LinJ.23.0620 & Oxidoreductase-like protein (OXR) & N.D. & \\
\hline Lin261G3 & -2.12 & $-1.1 \pm 0.3$ & 0.028 & 0 & 0 & a & LinJ.18.0370 & Tubulin tyrosine ligase, putative (TubTyrL) & + & $-10.1 \pm 0.5$ \\
\hline Lin264E4 & -2.15 & $-1.1 \pm 0.1$ & 0.003 & 0 & 0 & a & LinJ.28.1250 & Long chain fatty acid:coenzyme $\mathrm{A}$ ligase, putative (LC-FACL) & N.D. & \\
\hline Lin289A6 & -2.01 & $-1.0 \pm 0.5$ & 0.011 & 0 & 0 & $\mathrm{~b}$ & LinJ.11.1240 & $\mathrm{ABC}$ transporter, putative & N.D. & \\
\hline Lin300A3 & -2.28 & $-1.2 \pm 0.2$ & 0.032 & 0 & 0 & $\mathrm{~b}$ & LinJ.31.1870 & Protein kinase-like protein $(\mathrm{PK})$ & N.D. & \\
\hline Lin312B11 & -2.15 & $-1.1 \pm 0.2$ & 0.019 & $3 \mathrm{e}-169$ & $5 e-171$ & $\mathrm{~b}$ & LinJ.34.3460 & Vacuolar ATP synthase $\alpha$ catalytic subunit, putative (vATPs $\alpha$ ) & N.D. & \\
\hline
\end{tabular}

Features described: clone number, fold change (down-regulation if $F \leq-2.0$ ), $\log _{2} \mathrm{~F}$ and standard deviation (SD), Student's t-test $p$-value (p), clone definition (Def.; see Methods), TriTrypDB identifier, annotated gene function (including abbreviations defined in the text) and qRT-PCR outcome. Genes in grey (clones that overlap with more than one annotated gene): they are not differentially regulated (confirmed by qRT-PCR) or there is no evidence to support that they are differentially regulated in other cases (not determined by qRT-PCR)

protein-protein interactions in other organisms such RNase inhibitors, tropomyosin, tropomodulin and tolllike receptors. Each LRR motif has a sheet-turn-helix structure [44].

\section{Metabolism, transport and signal transduction}

The dihydrolipoamide dehydrogenase gene (DHLDH) is up-regulated in Pro-Pper, as well as some genes that participate in the respiratory chain. Namely, the cytochrome oxidase VIII subunit (coxVIII), the ATPase subunit 9 (ATPsu.9) and the F1 $\gamma$ subunit of the ATP synthetase $(\mathrm{F} 1 \gamma)$.

The up-regulation of the $\alpha$-ketoisovalerate dehydrogenase gene $(\mathrm{KIVDH})$ and the down-regulation of the methylcrotonyl-CoA carboxylase biotinylated subunit gene (MCCbt) suggest that isoleucine and valine catabolism may be favored in Pro-Pper, in agreement with the EC 1.2.4.4 and 6.4.1.4 activities of the KIVDH and MCCbt (Tables 2 and 3; TriTrypDB) within the KEGG pathway lif00280 [45].

A thiolase I gene (ACAT) is up-regulated in Pro-Pper, thus suggesting that $\beta$-oxidation of fatty acids is more active in this population than in Pro-PNA ${ }^{-}$. On the opposite, the long chain fatty acid:CoA ligase gene (LCFACL) is down-regulated, which suggests that long chain fatty acids are a more common source for Pro-PNA ${ }^{-}$to feed the $\beta$-oxidation degradation pathway or to contribute to fatty acid, glycerolipid and phospholipid biosynthesis (EC 6.2.1.3. activity in KEGG pathways ec00071 and ec00061, respectively). The lipin gene is also down-regulated and it is involved in glycerolipid biosynthesis. Consequently, these data suggest that $\beta$-oxidation is more active in Pro-Pper, whereas the lipid biosynthetic processes would be favored in Pro-PNA ${ }^{-}$. Both pathways provide molecules that are active in signaling processes [46]. The sphingolipid biosynthetic pathway may be more active in Pro-Pper as suggested by up-regulation of the sphingolipid $\Delta^{4}$-desaturase gene (DECS). Sphingolipids are also able to develop signaling functions in the parasite [47].

Protein kinases of these parasites have been identified [48] but most signaling pathways are still not known in these organisms yet [49]. The genes encoding a serine/ threonine protein phosphatase 1 LinJ.34.0840 (PP1), a serine/threonine protein phosphatase 2 catalytic subunit A2 (PP2B-A2), a dual specificity protein phosphatase (DualPP) and three PKs are up-regulated, whereas the phosphatidylinositol 3-kinase gene (PI3K) and a protein kinase gene $(\mathrm{PK})$ are down-regulated.

The genes encoding the $\alpha$ subunit of the vacuolar ATP synthetase (vATPS $\alpha$ ) and the ABC transporters ABCE and ABC LinJ.11.0040 are up-regulated in Pro-Pper, whereas the multidrug resistance protein (MRP), the ABC LinJ.11.1240 and the ABC1 are down-regulated. Finally, a nucleotide binding protein (NBP-MRP), probably an MRP (see LinJ.21.0720 entry in TriTrypDB), is also down-regulated.

\section{Cytoskeleton}

Several genes encoding actin- and tubulin-interacting proteins (AIP and TIP) are up-regulated in Pro-Pper. The AIPs are the profilin, two ADP-ribosylation factors (ARF LinJ.31.2350 and ARF3) and the tubulin-tyrosine ligase 


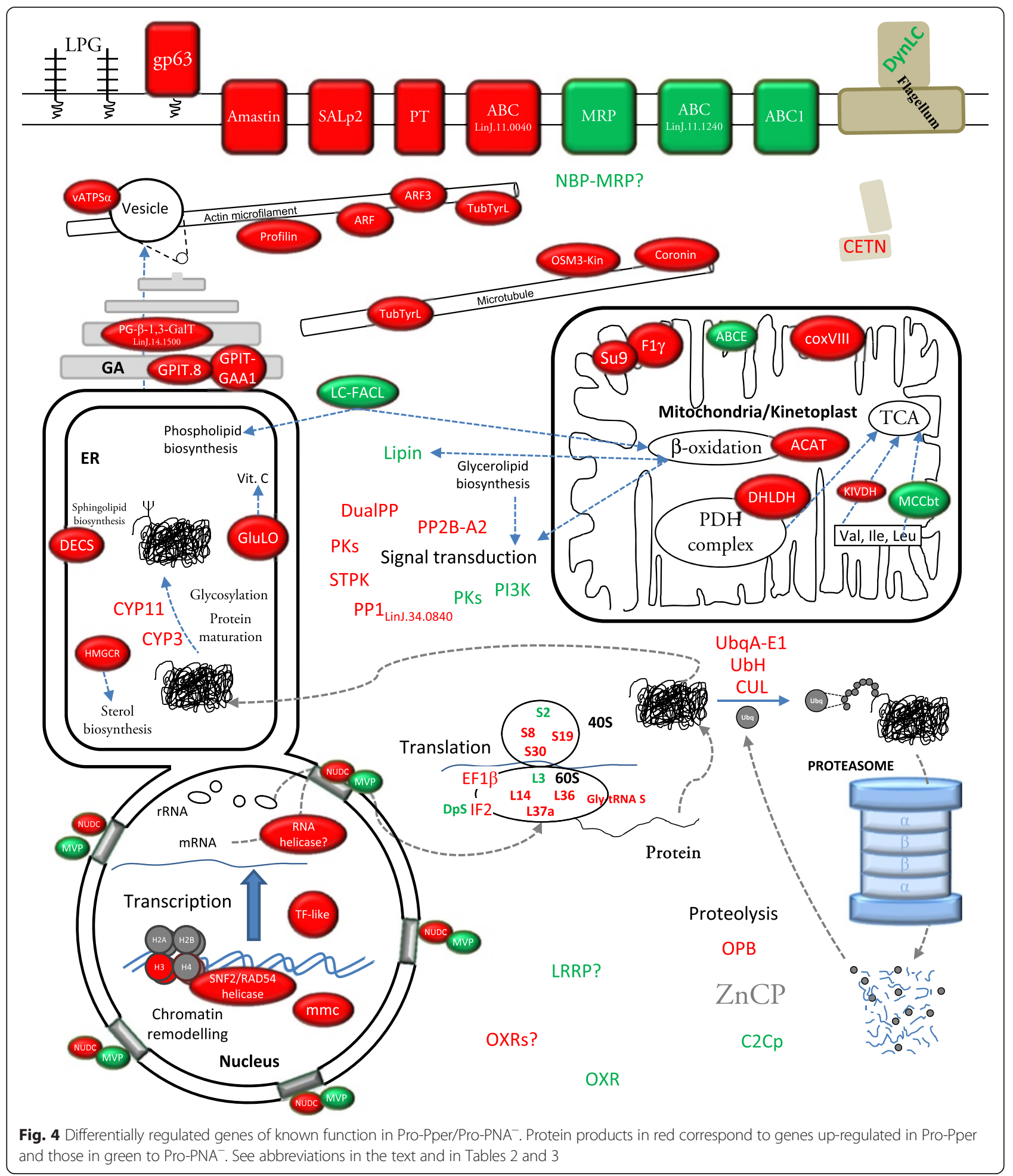

(TubTyrL). The TubTyrL is also a TIP, as well as a coronin and the OSM3-like kinesin. A different ARF gene (LinJ.04.0470) is down-regulated. The ARF1 has been characterized in T. cruzi and in L. donovani, where it is involved in coatomer assembly in budding vessicles in the secretory pathway and endocytosis $[50,51]$. The profilin may be involved in the actin microfilament polymerization machinery [52]. Coronins of Leishmania spp., Trypanosoma spp. and other protozoan parasites are involved in proliferation, locomotion and phagocytosis [53]. 


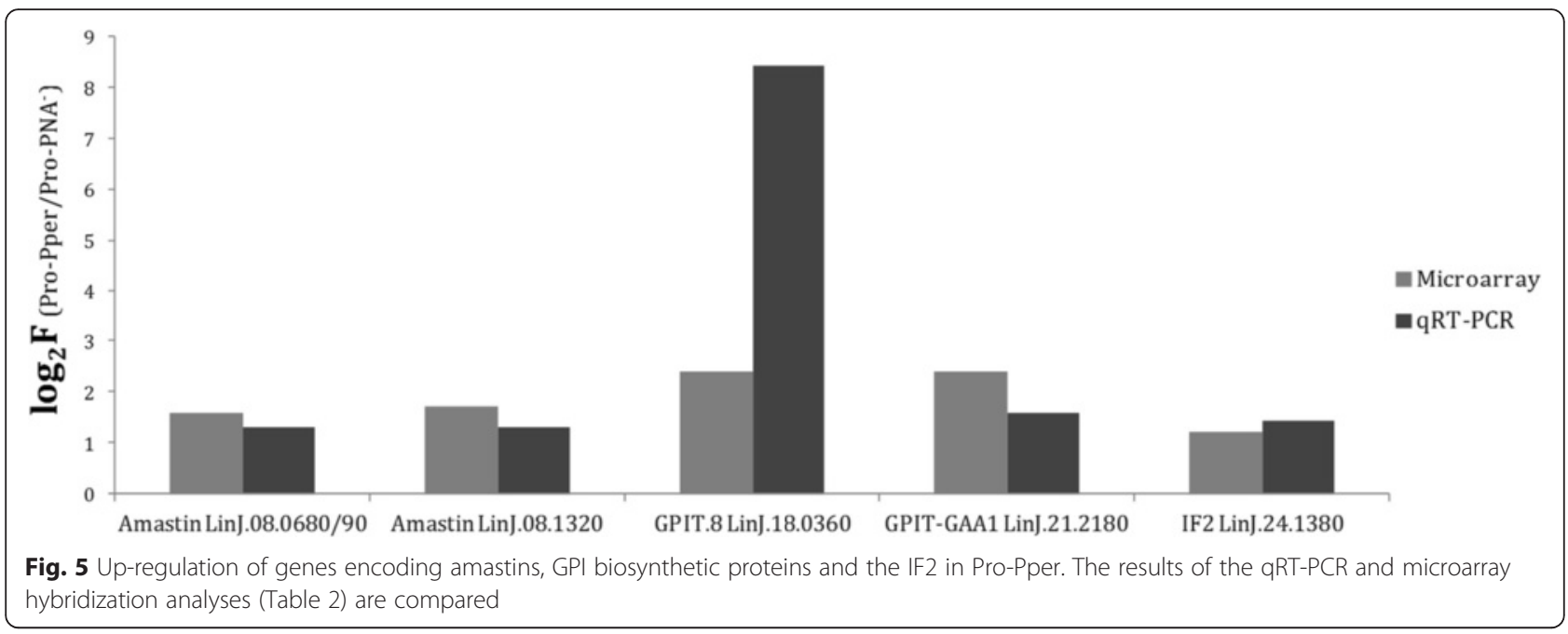

\section{Surface molecules}

Biosynthesis of glycosylphosphatidylinositol (GPI) may be increased in Pro-Pper, as the genes encoding the GPI transamidase GAA1 component (GPIT-GAA1) and the GPI transamidase subunit 8 (GPIT.8) are up-regulated. The GPI is an essential anchor of important surface molecules, such as the gp63 metalloprotease. One of the genes encoding a gp63 is up-regulated in Pro-Pper. The gp63 has been traditionally associated to metacyclic promastigotes and increased infectivity [12,54-56]. The GPI is also the essential anchor for glycosylinositolphospholipids (GIPLs) and other surface proteins of the amastigote glycocalix. GIPLs act as receptors for the host cell and as a shield for resistance against lysosomal hydrolases [57]. The GPI anchor is essential for the biosynthesis of GIPLs, which may partially explain the importance of up-regulating GPI-biosynthetic enzymes in metacyclic promastigotes, according to the pre-adaptation hypothesis $[24,58,59]$. The phosphoglycan $\beta$-1,3-galactosyltransferase (PG $\beta 1,3 \mathrm{GalT}$ ), also up-regulated in Pro-Pper, is involved in the biosynthesis of the lipophosphoglycan (LPG) and proteophosphoglycans (PPG), which are major surface molecules of promastigotes. The LPG is modified during promastigote differentiation, which makes possible negative selection with PNA.

The amastin superfamily genes LinJ.08.0680/0690/1320 are up-regulated in Pro-Pper vs. Pro-PNA ${ }^{-}$. They were described to be down-regulated in logarithmic phase promastigotes with respect to stationary phase promastigotes [24]. Some of these genes are up-regulated when temperature is raised and $\mathrm{pH}$ decreased both in axenic and intracellular amastigotes [24, 60]. Initially, these molecules were thought to be specific of the amastigote stage, but over-expression was also detected in stationary phase promastigotes and metacyclic promastigotes. Hence, they are up-regulated in advance prior to the differentiation process of promastigotes to amastigotes, according to the pre-adaptation hypothesis $[24,58,59]$.

Genes related with infectivity and preparation in advance to life in the phagolysosome

A $\mathrm{Zn}$ carboxypeptidase gene from the family M14 $(\mathrm{ZnCP})$ is up-regulated in Pro- $\mathrm{PNA}^{-}$with respect to Pro- $\mathrm{PNA}^{+}[26]$. Despite it is not differentially regulated between Pro-Pper and Pro-PNA ${ }^{-}$, we found that it is upregulated in Pro-Pper with respect to the whole stationary phase population [61]. This finding together with the differences in infectivity (Fig. 2) support that the degree of differentiation of the Pro-PNA ${ }^{-}$subpopulation is higher than the whole population in stationary phase as previously reported [26] but lower than Pro-Pper (Fig. 2). The significantly higher infectivity of Pro-Pper promastigotes in terms of rate of infected cells and number of amastigotes per infected cell are in agreement with the higher expression levels of the gp63 gene and GPI, LPG and PPG biosynthetic genes GPIT.8, GPIT-GAA1, PG- $\beta$ 1,3-GalT. Up-regulation of the SALp2 and amastin genes in Pro-Pper is also probably related. The Pearson correlation coefficient between Pro-Pper and Pro-PNA ${ }^{-}$in terms of differential gene expression (normalized fluorescence intensity values) is $R^{2}=0.68$. The meaning of this finding is that both populations are strongly correlated. However, it reveals important differences at the same time because it is not close to the maximum value (1). This is clearly appreciated in the shape of the M/A scatter plot (Fig. 3), which is a non-dispersed (rank $-4<$ $M<4$ ) dot-cloud simmetric about the $M=0$ line (i.e., lack of differential expression).

The gp63 gene, the GPI, LPG and PPG biosynthetic genes and others may be involved in preparation in advance for differentiation and survival of the amastigote stage in the phagolysosome according to the pre-adaptative 
hypothesis $[24,58,59]$. This is especially probable in the case of the amastin and the GPI biosynthetic protein genes.

\section{Conclusions}

The mean of amastigote counts per infected cell is significantly higher in Pro-Pper than in Pro-PNA ${ }^{-}$, as well as the rate of infected cells. Up-regulation of genes involved in GPI, LPG and PPG biosynthesis and a gp63 gene at the transcript level in Pro-Pper supports the differences found in infectivity. Consequently, the Pro-Pper population is more infective than the Pro- $\mathrm{PNA}^{-}$one. Therefore, Pro-PNA ${ }^{-}$are not as infective as Pro-Pper, but they are highly infective in any case. This means that enrichment in metacyclics by negative selection with PNA in culture is a good approach but not as good as isolation from the natural environment, i.e. the anterior thoracic midgut of the sand fly. Indeed, the Pearson correlation coefficient $\left(R^{2}=0.68\right)$ between both transcriptomes in terms of transcript abundance supports that the similarity between both populations is moderate and the important differences found are presumably related to increased infectivity in Pro-Pper. In other words, the correlation is sufficiently high to consider that both samples are physiologically comparable (i.e. the experiment was correctly designed and performed) and sufficiently low to conclude that important differences in transcript abundance have been found (including genes involved in chromatin structure, nucleocytoplasmic transport, gene expression regulation, signaling and other processes). Therefore, the implications of axenic culture should be evaluated case-by-case in each experimental design even when the stationary phase population is enriched in metacyclic promastigotes by negative selection with PNA.

\section{Additional files}

Additional file 1: Primers and TaqMan-MGB probes used for qRT-PCR validation and determination of differential expression in clones that represent more than one gene. Table S1. Sequences of qRT-PCR primers and probes. (XLS $33 \mathrm{~kb})$

Additional file 2: Microarray controls. Table S2. The results of the Pro-Per/Pro-PNA ${ }^{-}$cDNA:genomic-DNA-microarray hybridization analysis for positive and negative control spots. (DOC $48 \mathrm{~kb}$ )

Additional file 3: Hypothetical proteins. Table S3. Hypothetical protein genes up-regulated in Pro-Pper/Pro-PNA ${ }^{-}$. Table S4. Hypothetical protein genes down-regulated in Pro-Pper/Pro-PNA ${ }^{-}$. Table S5. Type $c$ and qPCR non-determined clones. (DOC 255 kb)

\section{Abbreviations}

aaRNA: doubly amplified mRNA; ABC: ATP-binding cassette; ACAT: thiolase I; AIP: actin-interacting protein; ARF: ADP-ribosylation factor; aRNA: amplified mRNA; ATPsu.9: ATPase subunit 9; C2cp: calpain-like cysteine peptidase, Clan CA, family C2; CETN: centrin; coxVIII: cytochrome oxidase subunit VIII; CYP: cyclophilin; DECS: sphingolipid $\Delta^{4}$-desaturase; DHLDH: dihydrolipoamide dehydrogenase; DpS: diphthine synthase; DualPP: dual specificity protein phosphatase; DynLC: dynein light chain; EF1ß: elongation factor $1 \beta$; GIPL: glycosylinositolphospholipid; gp63: 63 KDa glycoprotein, metalloprotease (leishmanolysin); GPI: glycosylphosphatidylinositol; GPIT.8: GPI transamidase subunit 8; GPIT-GAA1: GPI transamidase GAA1 component; HIFBS: heat-inactivated fetal bovine serum; HMGCR: 3hydroxymethylglutaryl-CoA reductase; IF2: initiation factor 2; KIVDH: 2ketoisovalerate dehydrogenase; LC-FACL: long chain fatty acid:CoA ligase; LPG: lipophosphoglycan; LRRP: leucine-reach repeat protein; MCCbt: methylcrotonyl-CoA carboxylase biotinylated subunit; mPPG: membrane-bound proteophosphoglycan; MRP: multidrug resistance protein; MVP: major vault protein; NBP: nucleotide-binding protein; NUDC: nuclear movement protein; OPB: oligopeptidase B; OXR: oxidoreductase; PDH: pyruvate dehydrogenase complex; PG $\beta 1$,3GalT: phosphoglycan $\beta-1,3$ galactosyltransferase; PI3K: phosphatidylinositol 3-kinase; PK: protein kinase; PNA: peanut agglutinin; PP1: Ser/Thr protein phosphatase 1; PP2B-A2: Ser/Thr protein phosphatase 2, catalytic subunit A2; Pro-PNA ${ }^{-}$: PNA non-agglutinating promastigotes; Pro-Pper: promastigotes isolated from the stomodeal valve of $P$. perniciosus; SALp2: surface antigen-like protein 2; SL-RNA: spliced leader RNA; SPPG: secreted proteophosphoglycan; TF: transcription factor; TIP: tubulininteracting protein; TOR: target of rapamycin; TubTyrL: tubulin tyrosine ligase; UbH: ubiquitin hydrolase; UbqA-E1: ubiquitin-activating enzyme E1;

VATPsa: vacuolar ATP synthetase, subunit a; VL: visceral leishmaniasis; ZnCP: zinc carboxypeptidase, family M14.

\section{Acknowledgments}

We thank Alfredo Toraño, Mercedes Domínguez, Víctor Parro and Manuel J. Gómez for their support. This project was funded through the Ramón Areces Foundation contract 050204100014 (OTT code 20100338). PJA thanks CSIC for the 13P-BPD2003-1 grant and two contracts of employment for a position included in the A1 group (respectively from January $16^{\text {th }}$ to July $23^{\text {rd }} 2008$ and from October $16^{\text {th }} 2008$ to April $15^{\text {th }}$ 2009). AA thanks CSIC for the JaeDoc contract 5072160068 W0SC000077 within the A1 group. MAD thanks the Spanish Ministry of Economy and Competitiveness for the FPI predoctoral fellowship BES-2011-047361.

\section{Availability of the supporting data}

Microarray hybridization data are available in the MIAME-compliant GEO repository (http://www.ncbi.nlm.nih.gov/geo/query/acc.cgi?acc=GSE70992). Particular information about the sequences of primers and TaqMan probes used, hybridization controls in the microarray experiment, hypothetical proteins and analysis by gene clustering is available in the Additional files associated to this manuscript. Gene identifiers listed in Tables 2 and 3 correspond to TriTrypDB.

\section{Authors' contributions}

All authors contributed to the intellectual content of the study and revised and approved the final manuscript. PJA, AA and VL conceived and designed the experiment. MIJ and RM performed the sand fly infection and dissection procedures and prepared Pro-Pper. MAD performed the in vitro infection assays. PJA, MIJ, MAD and RM prepared samples for microarray hybridization. PJA, MM and AA performed the microarray hybridization experiment. PJA and AA performed GRT-PCR analysis. PJA, AA and VL contributed to the thorough analysis and interpretation of the results and prepared the manuscript.

\section{Competing interests}

All authors declare that they have no competing interests.

\section{Author details}

${ }^{1}$ Laboratorio de Parasitología Molecular, Departamento de Microbiología Molecular y Biología de las Infecciones, Centro de Investigaciones Biológicas (Consejo Superior de Investigaciones Científicas), calle Ramiro de Maeztu, 9, 28040 Madrid, Spain. ${ }^{2}$ Laboratorio de Ecología Molecular, Centro de Astrobiología, (Instituto Nacional de Técnica Aeroespacial "Esteban

Terradas"-Consejo Superior de Investigaciones Científicas), ctra. de Ajalvir Km 4, 28850 Torrejón de Ardoz, Madrid, Spain. '3nidad de Entomología Médica, Servicio de Parasitología, Centro Nacional de Microbiología, Virología e Inmunología Sanitarias (Instituto de Salud Carlos III), ctra.

Majadahonda-Pozuelo s/n, 28220 Majadahonda, Madrid, Spain.

Received: 18 July 2015 Accepted: 26 April 2016

Published online: 20 May 2016 


\section{References}

1. Desjeux P. Leishmaniasis. Public health aspects and control. Clin Dermatol. 1996;14(5):417-23.

2. WHO. Report of a meeting of the WHO Expert Committee on the control of Leishmaniases. Geneva: WHO; 2010.

3. Pasquau F, Ena J, Sanchez R, Cuadrado JM, Amador C, Flores J, Benito C, Redondo C, Lacruz J, Abril V. Leishmaniasis as an opportunistic infection in HIV-infected patients: determinants of relapse and mortality in a collaborative study of 228 episodes in a Mediterreanean region. Eur J Clin Microbiol Infect Dis. 2005;24(6):411-8.

4. Cruz I, Nieto J, Moreno J, Canavate C, Desjeux P, Alvar J. Leishmania/HIV co-infections in the second decade. Indian J Med Res. 2006;123(3):357-88

5. Arce A, Estirado A, Ordobas M, Sevilla S, Garcia N, Moratilla L, de la Fuente S, Martinez AM, Perez AM, Aranguez E.

Re-emergence of leishmaniasis in Spain: community outbreak in Madrid, Spain, 2009 to 2012. Euro Surveill. 2013;18(30):20546.

6. Molina R, Jimenez MI, Cruz I, Iriso A, Martin-Martin I, Sevillano O, Melero S, Bernal J. The hare (Lepus granatensis) as potential sylvatic reservoir of Leishmania infantum in Spain. Vet Parasitol. 2012;190(1-2):268-71.

7. Jimenez M, Gonzalez E, Martin-Martin I, Hernandez S, Molina R. Could wild rabbits (Oryctolagus cuniculus) be reservoirs for Leishmania infantum in the focus of Madrid, Spain? Vet Parasitol. 2014;202(3-4):296-300.

8. da Silva R, Sacks DL. Metacyclogenesis is a major determinant of Leishmania promastigote virulence and attenuation. Infect Immun. 1987;55(11):2802-6.

9. Gossage SM, Rogers ME, Bates PA. Two separate growth phases during the development of Leishmania in sand flies: implications for understanding the life cycle. Int J Parasitol. 2003;33(10):1027-34

10. Rioux JA, Guilvard E, Gállego J, Moreno G, Pratlong F, Portús M, Rispail P Gállego M, Bastien P. Phlebotomus ariasi Tonnoir, 1921 et Phlebotomus perniciosus Newstead, 1911 vecteurs du complexe Leishmania infantum dans un même foyer. Infestations par deux zymodèmes syntopiques. A propos d'une enquête

en Catalogne (Espagne). In: Rioux JA, editor. "Leishmania" Taxonomie et phylogenèse Applications éco-épidémiologiques Int Coll CNRS/INSERM/ OMS 1984. Montpellier: Institut Méditerranéen d'Etudes Epidémiologiques et Ecologiques; 1986. p. 439-44.

11. Killick-Kendrick R. The biology and control of phlebotomine sand flies. Clin Dermatol. 1999;17(3):279-89.

12. Joshi PB, Sacks DL, Modi G, McMaster WR. Targeted gene deletion of Leishmania major genes encoding developmental stage-specific leishmanolysin (GP63). Mol Microbiol. 1998;27(3):519-30.

13. McConville MJ, Mullin KA, Ilgoutz SC, Teasdale RD. Secretory pathway of trypanosomatid parasites. Microbiol Mol Biol Rev. 2002;66(1):122-54. table of contents.

14. Pimenta PF, Turco SJ, McConville MJ, Lawyer PG, Perkins PV, Sacks DL. Stage-specific adhesion of Leishmania promastigotes to the sandfly midgut. Science. 1992;256(5065):1812-5.

15. Sacks DL, Perkins PV. Identification of an infective stage of Leishmania promastigotes. Science. 1984;223(4643):1417-9.

16. Sacks DL, Perkins PV. Development of infective stage Leishmania promastigotes within phlebotomine sand flies. AmJTrop Med Hyg. 1985;34(3):456-9.

17. Neal RA, Miles RA. Heated blood agar medium for the growth of Trypanosoma cruzi and some species of Leishmania. Nature. 1963;198:210-1.

18. Lemma A, Schiller EL. Extracellular cultivation of the leishmanial bodies of species belonging to the Protozoan Genus Leishmania. Exp Parasitol. 1964;15:503-13.

19. Steiger RF, Steiger E. A defined medium for cultivating Leishmania donovani and L. braziliensis. J Parasitol. 1976;62(6):1010-1.

20. Berens RL, Marr JJ. An easily prepared defined medium for cultivation of Leishmania donovani promastigotes. J Parasitol. 1978;64(1):160.

21. Zilberstein D. Physiological and biochemical aspects of Leishmania development. In: Myler P, Fassel N, editors. Leishmania after the genome. Norfolk: Caister Academic Press; 2008. p. 107-22.

22. Zuckerman A, Lainson R. Leishmania. In: Kreier JP, editor. Parasitic protozoa. New York: Academic; 1977. p. 66-86.

23. Alcolea PJ, Alonso A, Gomez MJ, Postigo M, Molina R, Jimenez M, Larraga V. Stage-specific differential gene expression in Leishmania infantum: from the foregut of Phlebotomus perniciosus to the human phagocyte. BMC Genomics. 2014;15:849.

24. Alcolea PJ, Alonso A, Gomez MJ, Moreno I, Dominguez M, Parro V, Larraga V. Transcriptomics throughout the life cycle of Leishmania infantum: high down-regulation rate in the amastigote stage. Int J Parasitol. 2010;40(13):1497516.

25. McConville MJ, Turco SJ, Ferguson MA, Sacks DL. Developmental modification of lipophosphoglycan during the differentiation of Leishmania major promastigotes to an infectious stage. EMBO J. 1992;11(10):3593-600.

26. Alcolea PJ, Alonso A, Sanchez-Gorostiaga A, Moreno-Paz M, Gomez MJ, Ramos I, Parro V, Larraga V. Genome-wide analysis reveals increased levels of transcripts related with infectivity in peanut lectin non-agglutinated promastigotes of Leishmania infantum. Genomics. 2009;93(6):551-64.

27. Sacks DL, Hieny S, Sher A. Identification of cell surface carbohydrate and antigenic changes between noninfective and infective developmental stages of Leishmania major promastigotes. J Immunol. 1985;135(1):564-9.

28. Sacks DL. Metacyclogenesis in Leishmania promastigotes. Exp Parasitol. 1989;69(1):100-3.

29. Spath GF, Beverley SM. A lipophosphoglycan-independent method for isolation of infective Leishmania metacyclic promastigotes by density gradient centrifugation. Exp Parasitol. 2001;99(2):97-103.

30. Alcolea PJ, Alonso A, Garcia-Tabares F, Torano A, Larraga V. An Insight into the proteome of Crithidia fasciculata choanomastigotes as a comparative approach to axenic growth, peanut lectin agglutination and differentiation of Leishmania spp. promastigotes. PLoS One. 2014;9(12), e113837.

31. Sundstrom C, Nilsson K. Establishment and characterization of a human histiocytic lymphoma cell line (U-937). Int J Cancer. 1976;17(5):565-77.

32. Minta JO, Pambrun L. In vitro induction of cytologic and functional differentiation of the immature human monocytelike cell line U-937 with phorbol myristate acetate. Am J Pathol. 1985;119(1):111-26.

33. Molina R. Experimental infections of a Phlebotomus perniciosus colony using different procedures. Parassitologia. 1991;33(Suppl):425-9.

34. Molina R. Laboratory adaptation of an autochtonous colony of Phlebotomus perniciosus Newstead, 1911 (Diptera: Psychodidae). Res Rev Parasitol. 1911; 1991(51):87-9.

35. Bookout AL, Cummins CL, Mangelsdorf DJ, Pesola JM, Kramer MF. Highthroughput real-time quantitative reverse transcription PCR. In: Ausubel FM et al., editors. Current protocols in molecular biology. 2006. Chapter 15:Unit 1518 .

36. Charest H, Zhang WW, Matlashewski G. The developmental expression of Leishmania donovani A2 amastigote-specific genes is post-transcriptionally mediated and involves elements located in the 3'-untranslated region. J Biol Chem. 1996;271(29):17081-90.

37. Lahav T, Sivam D, Volpin H, Ronen M, Tsigankov P, Green A, Holland N, Kuzyk M, Borchers C, Zilberstein D, et al. Multiple levels of gene regulation mediate differentiation of the intracellular pathogen Leishmania. FASEB J. 2011 25(2):515-25.

38. Parsons M, Myler PJ, Berriman M, Roos DS, Stuart KD. Identity crisis? The need for systematic gene IDs. Trends Parasitol. 2011;27(5):183-4.

39. Soto M, Requena JM, Quijada L, Alonso C. Organization, transcription and regulation of the Leishmania infantum histone H3 genes. Biochem J. 1996; 318(Pt 3):813-9.

40. Slovak ML, Ho JP, Cole SP, Deeley RG, Greenberger L, de Vries EG, Broxterman HJ, Scheffer GL, Scheper RJ. The LRP gene encoding a major vault protein associated with drug resistance maps proximal to MRP on chromosome 16: evidence that chromosome breakage plays a key role in MRP or LRP gene amplification. Cancer Res. 1995;55(19):4214-9.

41. Saldivia M, Barquilla A, Bart JM, Diaz-Gonzalez R, Hall MN, Navarro M. Target of rapamycin (TOR) kinase in Trypanosoma brucei: an extended family. Biochem Soc Trans. 2013;41(4):934-8.

42. Alcolea PJ, Alonso A, Larraga V. Genome-wide gene expression profile induced by exposure to cadmium acetate in Leishmania infantum promastigotes. Int Microbiol. 2011;14(1):1-11.

43. Moehring JM, Moehring TJ. The post-translational trimethylation of diphthamide studied in vitro. J Biol Chem. 1988;263(8):3840-4.

44. Kobe B, Deisenhofer J. The leucine-rich repeat: a versatile binding motif. Trends Biochem Sci. 1994;19(10):415-21.

45. Kanehisa M, Goto S, Kawashima S, Okuno Y, Hattori M. The KEGG resource for deciphering the genome. Nucleic Acids Res. 2004;32(Database issue):D277-80.

46. Zhang K, Beverley SM. Phospholipid and sphingolipid metabolism in Leishmania Mol Biochem Parasitol. 2010;170(2):55-64

47. Zhang K, Bangs JD, Beverley SM. Sphingolipids in parasitic protozoa Adv Exp Med Biol. 2010;688:238-48.

48. Parsons M, Worthey EA, Ward PN, Mottram JC. Comparative analysis of the kinomes of three pathogenic trypanosomatids: Leishmania major, Trypanosoma brucei and Trypanosoma cruzi. BMC Genomics. 2005;6:127. 
49. Parsons M, Ruben L. Pathways involved in environmental sensing in trypanosomatids. Parasitol Today. 2000;16(2):56-62.

50. de Sa-Freire A, Nepomuceno-Silva JL, da Paixao JC, de Mendonca SM, de Melo LD, Lopes UG. TcArf1: a Trypanosoma cruzi ADP-ribosylation factor. Parasitol Res. 2003;91 (2):166-70.

51. Porter-Kelley JM, Gerald NJ, Engel JC, Ghedin E, Dwyer DM. LdARF1 in trafficking and structural maintenance of the trans-Golgi cisternal network in the protozoan pathogen Leishmania donovani. Traffic. 2004;5(11):868-83.

52. Marion S, Laurent C, Guillen N. Signalization and cytoskeleton activity through myosin IB during the early steps of phagocytosis in Entamoeba histolytica: a proteomic approach. Cell Microbiol. 2005;7(10):1504-18.

53. Xavier CP, Eichinger L, Fernandez MP, Morgan RO, Clemen CS. Evolutionary and functional diversity of coronin proteins. Subcell Biochem. 2008:48:98-109.

54. Halle M, Gomez MA, Stuible M, Shimizu H, McMaster WR, Olivier M,Tremblay ML. The Leishmania surface protease GP63 cleaves multiple intracellular proteins and actively participates in p38 mitogen-activated protein kinase inactivation.

J Biol Chem. 2009;284(11):6893-908.

55. Brittingham A, Morrison CJ, McMaster WR, McGwire BS, Chang KP, Mosser DM. Role of the Leishmania surface protease gp63 in complement fixation cell adhesion, and resistance to complement-mediated lysis. J Immunol. 1995:155(6):3102-11.

56. Shio MT, Eisenbarth SC, Savaria M, Vinet AF, Bellemare MJ, Harder KW, Sutterwala FS, Bohle DS, Descoteaux A, Flavell RA, et al. Malarial hemozoin activates the NLRP3 inflammasome through Lyn and Syk kinases. PLoS Pathog. 2009:5(8), e1000559.

57. Blackwell JM, Ezekowitz RA, Roberts MB, Channon JY, Sim RB, Gordon S. Macrophage complement and lectin-like receptors bind Leishmania in the absence of serum. J Exp Med. 1985;162(1):324-31.

58. Bates PA. Leishmania sand fly interaction: progress and challenges. Curr Opin Microbiol. 2008;11(4):340-4.

59. Depledge DP, Evans KJ, Ivens AC, Aziz N, Maroof A, Kaye PM, Smith DF. Comparative expression profiling of Leishmania: modulation in gene expression between species and in different host genetic backgrounds. PLoS Negl Trop Dis. 2009;3(7), e476.

60. Alcolea PJ, Alonso A, Gomez MJ, Sanchez-Gorostiaga A, Moreno-Paz M, Gonzalez-Pastor E, Torano A, Parro V, Larraga V. Temperature increase prevails over acidification in gene expression modulation of amastigote differentiation in Leishmania infantum. BMC Genomics. 2010:11:31.

61. Alcolea PJ, Alonso A, Domínguez M, Parro V, Jiménez M, Molina R, Larraga $\checkmark$. Influence of the microenvironment in the transcriptome of Leishmania infantum promastigotes: sand fly versus culture. PLoS Negl Trop Dis. 2016; 10(5):e0004693.

\section{Submit your next manuscript to BioMed Central and we will help you at every step:}

- We accept pre-submission inquiries

- Our selector tool helps you to find the most relevant journal

- We provide round the clock customer support

- Convenient online submission

- Thorough peer review

- Inclusion in PubMed and all major indexing services

- Maximum visibility for your research

Submit your manuscript at www.biomedcentral.com/submit 